OPEN ACCESS

Edited by:

Weiwen Zhang,

Tianjin University, China

Reviewed by:

Michael Allan Conlon,

Commonwealth Scientific

and Industrial Research Organisation,

Australia

Ethan I. Lan

National Chiao Tung University,

Taiwan

Richard P. Darveau,

University of Washington, USA

*Correspondence:

Yasuo Yoshida

yasuoy@dpc.agu.ac.jp

Specialty section:

This article was submitted to

Microbial Physiology and Metabolism,

a section of the journal

Frontiers in Microbiology

Received: 31 May 2016

Accepted: 08 July 2016

Published: 19 July 2016

Citation

Sato M, Yoshida Y, Nagano K,

Hasegawa Y, Takebe $J$ and

Yoshimura F (2016) Three

CoA Transferases Involved

in the Production of Short Chain Fatty

Acids in Porphyromonas gingivalis.

Front. Microbiol. 7:1146.

doi: 10.3389/fmicb.2016.01146

\section{Three CoA Transferases Involved in the Production of Short Chain Fatty Acids in Porphyromonas gingivalis}

\author{
Mitsunari Sato ${ }^{1,2}$, Yasuo Yoshida ${ }^{1 *}$, Keiji Nagano' ${ }^{1}, Y_{0}$ Shiaki Hasegawa1, Jun Takebe ${ }^{2}$ and \\ Fuminobu Yoshimura ${ }^{1}$
}

\begin{abstract}
'Department of Microbiology, School of Dentistry, Aichi Gakuin University, Nagoya, Japan, ${ }^{2}$ Department of Removable Prosthodontics, School of Dentistry, Aichi Gakuin University, Nagoya, Japan
\end{abstract}

Butyryl-CoA:acetate CoA transferase, which produces butyrate and acetyl-CoA from butyryl-CoA and acetate, is responsible for the final step of butyrate production in bacteria. This study demonstrates that in the periodontopathogenic bacterium Porphyromonas gingivalis this reaction is not catalyzed by PGN_1171, previously annotated as butyryl-CoA:acetate CoA transferase, but by three distinct CoA transferases, PGN_0725, PGN_1341, and PGN_1888. Gas chromatography/mass spectrometry (GC-MS) and spectrophotometric analyses were performed using crude enzyme extracts from deletion mutant strains and purified recombinant proteins. The experiments revealed that, in the presence of acetate, PGN_0725 preferentially utilized butyryl-CoA rather than propionyl-CoA. By contrast, this preference was reversed in PGN_1888. The only butyryl-CoA:acetate CoA transferase activity was observed in PGN_1341. Double reciprocal plots revealed that all the reactions catalyzed by these enzymes follow a ternary-complex mechanism, in contrast to previously characterized CoA transferases. GC-MS analysis to determine the concentrations of short chain fatty acids (SCFAs) in culture supernatants of $P$. gingivalis wild type and mutant strains revealed that PGN_0725 and PGN_1888 play a major role in the production of butyrate and propionate, respectively. Interestingly, a triple deletion mutant lacking PGN_0725, PGN_1341, and PGN_1888 produced low levels of SCFAs, suggesting that the microorganism contains CoA transferase(s) in addition to these three enzymes. Growth rates of the mutant strains were mostly slower than that of the wild type, indicating that many carbon compounds produced in the SCFA synthesis appear to be important for the biological activity of this microorganism.

Keywords: Porphyromonas gingivalis, butyrate, CoA transferase, short chain fatty acid, propionate

\section{INTRODUCTION}

Periodontal diseases are a group of inflammatory conditions that lead to the destruction of tooth-supporting tissues and appear to be associated with serious systemic conditions (Kumar, 2013). Among the periodontitis-associated bacteria, Porphyromonas gingivalis is the best-studied periodontal pathogen.

Abbreviations: OD600, optical density at 600428 nm; PBS, phosphate buffered saline; SCFAs, short chain fatty acids. 
Porphyromonas gingivalis, which is a Gram-negative, black-pigmented, asaccharolytic anaerobe, is implicated in the initiation and progression of periodontal diseases (Lamont and Jenkinson, 2000). Its primary niche is the anaerobic environment of the sub-gingival pockets (Lamont and Jenkinson, 1998; Yoshida et al., 2003). This organism produces a variety of potential virulence factors, such as fimbriae, hemagglutinins, lipopolysaccharide, capsular polysaccharide, vesicles, outer membrane proteins, and proteolytic enzymes (Holt et al., 1999; Lamont and Jenkinson, 2000; How et al., 2016). P. gingivalis also releases large amounts of butyrate and propionate into its culture medium (Niederman et al., 1996; Imai et al., 2012). These molecules easily penetrate the periodontal tissue because of their low molecular weights (Tonetti et al., 1987) and subsequently disturb host cell activity and host defense systems (Singer and Buckner, 1981; Eftimiadi et al., 1990; Kurita-Ochiai et al., 1995). Concentrations of these molecules in the periodontal pockets significantly correlate with the clinical measure of disease severity and inflammation (Niederman et al., 1997; Qiqiang et al., 2012). Furthermore, butyrate, which induces apoptosis in gingival fibroblasts and in T- and B-cells (Kurita-Ochiai et al., 1995, 2000, 2008; Chang et al., 2013), is the most toxic metabolic end product found in the oral cavity (Niederman et al., 1997). In the gastrointestinal tract, however, butyrate produced by bacteria is thought to play an important and beneficial role (Siavoshian et al., 2000; Peng et al., 2009; Plöger et al., 2012; Qin et al., 2012; Le Chatelier et al., 2013; Mathewson et al., 2016).

Two different pathways for the synthesis of butyrate from butyryl-CoA have been characterized to date. The first pathway involves phosphotransbutyrylase and butyrate kinase, with butyryl-CoA converted to butyrate through the formation of a butyryl phosphate intermediate. This pathway was identified in Clostridium acetobutylicum (Walter et al., 1993). In the second pathway, butyryl-CoA:acetate CoA transferase transfers the CoA moiety from butyryl-CoA to an exogenous acetate molecule, resulting in the formation of acetyl-CoA and butyrate (Duncan et al., 2002). A screen of butyrate-producing isolates from the human gut suggested that the latter pathway is more prevalent than the former (Louis et al., 2004). A biochemical study using crude enzyme extracts suggested that the latter pathway is also operational in P. gingivalis (Takahashi et al., 2000). PGN_1171 was annotated as the CoA transferase associated with the last step of butyrate production in P. gingivalis ATCC 33277 (Nelson et al., 2003; Hendrickson et al., 2009).

We recently reported the identification and characterization of two reductases that produce succinate semialdehyde and 4hydroxybutyrate, both of which are intermediates of the butyrate synthetic pathway of $P$. gingivalis (Yoshida et al., 2015, 2016). We are now extending molecular studies of the butyrate production pathway to the final step of the pathway (Figure 1). In this study, we first demonstrate that PGN_1171 is not involved in the reaction of butyrate production from butyryl-CoA, and, instead, we identify three candidate CoA transferases using a homology search with CoA transferase in Roseburia hominis, which is an anaerobic intestinal bacterium (Charrier et al., 2006; Travis et al., 2015). To understand their roles in butyrate production in $P$. gingivalis, several deletion strains were constructed, and short chain fatty acids (SCFAs) in their supernatants were quantified and analyzed. In addition, the genes encoding the putative enzymes were cloned and expressed in Escherichia coli, and the recombinant proteins were purified and then enzymatically characterized.

\section{MATERIALS AND METHODS}

\section{Bacterial Strains and Culture Conditions}

Porphyromonas gingivalis strains used in this study are listed in Table 1, and were grown anaerobically at $37^{\circ} \mathrm{C}$ in a modified GAM broth (Nissui, Tokyo, Japan) or on Brucella HK agar plates (Kyokuto Pharmaceutical Industrial, Tokyo, Japan), supplemented with $5 \%$ rabbit blood. The following antibiotic concentrations were used, as appropriate: $20 \mu \mathrm{g} / \mathrm{ml}$ erythromycin, $0.5 \mu \mathrm{g} / \mathrm{ml}$ tetracycline, and/or $10 \mu \mathrm{g} / \mathrm{ml}$ ampicillin. E. coli DH5 $\alpha$ and BL21 (DE3) strains were grown aerobically at $37^{\circ} \mathrm{C}$ in $2 \times \mathrm{YT}$ medium (Becton Dickinson Japan, Tokyo, Japan) with $100 \mu \mathrm{g} / \mathrm{ml}$ ampicillin, $200 \mu \mathrm{g} / \mathrm{ml}$ erythromycin, or $10 \mu \mathrm{g} / \mathrm{ml}$ tetracycline.

\section{Construction of $P$. gingivalis Mutant Strains}

Porphyromonas gingivalis deletion mutants lacking PGN_1171, PGN_0725, PGN_1341, and/or PGN_1888 gene were constructed by replacing each gene with ermF and ermB (erm cassette), as previously described (Yoshida et al., 2015). Approximately 0.7-kb-long upstream and downstream flanking fragments of each gene were PCR-amplified from genomic DNA of $P$. gingivalis ATCC 33277 using primers listed in Supplementary Table S1. The erm cassette was amplified from plasmid pVA2198 (Fletcher et al., 1997). The amplicons were joined using mixed PCR (Horton et al., 1989) or the In-fusion HD Cloning kit (Takara Bio, Otsu, Japan), and subcloned into pUC19 (GE Healthcare Japan, Hino, Japan). The resulting plasmids are listed in Table 1. Ligated fragments were introduced into P. gingivalis ATCC 33277 by electroporation. The constructed mutants were designated PGAGU101 (PGN_1171::erm), PGAGU104 (PGN_0725::erm), PGAGU108 (PGN_1888::erm), and PGAGU109 (PGN_1341::erm). To create double mutants, tetracycline resistance gene tetQ, amplified from plasmid pT-COW (Gardner et al., 1996), was used as an additional selectable marker. The tetQ gene and flanking fragments of the targeted genes were joined as described above, and used for electroporation of $P$. gingivalis single mutant strains to obtain PGAGU111 (PGN_0725::erm PGN_1888::tetQ), PGAGU114 (PGN_1341::erm PGN_1888::tetQ), or PGAGU115 (PGN_0725::tetQ PGN_1341::erm). A triple mutant strain lacking PGN_0725, PGN_1341, and PGN_1888 was also constructed, by replacing PGN_1888 in PGAGU115 with the ampicillin resistance gene серA. The серA gene was amplified from plasmid pCEPA, kindly provided by Dr. Naito (Nagasaki University, Nagasaki, Japan). The resultant mutant strain was designated PGAGU118 (PGN_0725::tetQ PGN_1341::erm PGN_1888::серA). The integration of ligated PCR products at the expected chromosomal location(s) was confirmed by 


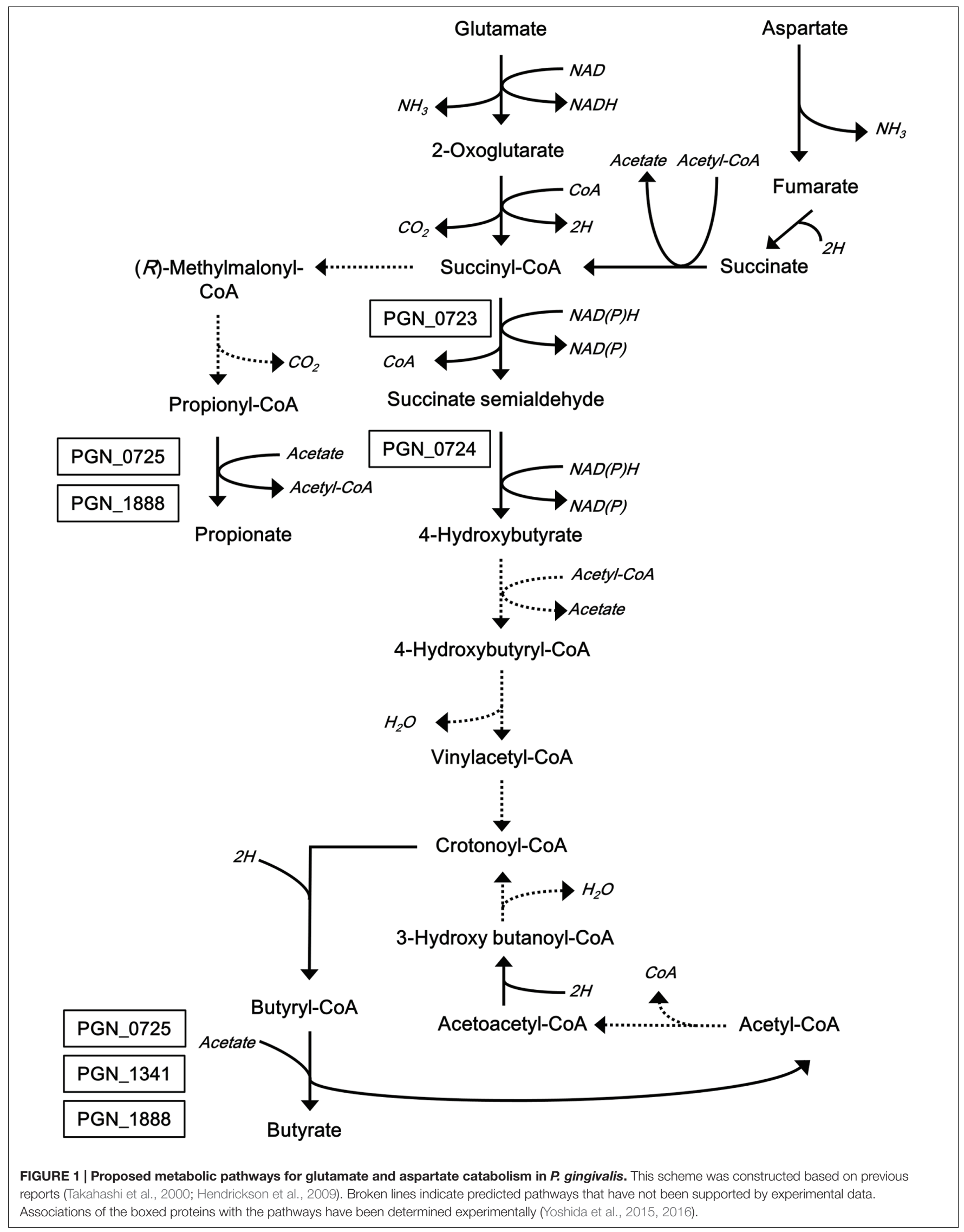


TABLE 1 | Porphyromonas gingivalis strains and plasmids used in this study.

\begin{tabular}{|c|c|c|}
\hline Strain and plasmid & Relevant characteristics & Reference \\
\hline \multicolumn{3}{|l|}{$P$ gingivalis } \\
\hline ATCC 33277 & Wild type & ATCC \\
\hline PGAGU101 & P. gingivalis ATCC 33277 containing the erm cassette in place of PGN_1171 & This study \\
\hline PGAGU104 & P. gingivalis ATCC 33277 containing the erm cassette in place of PGN_0725 & This study \\
\hline PGAGU108 & P. gingivalis ATCC 33277 containing the erm cassette in place of PGN_1888 & This study \\
\hline PGAGU109 & P. gingivalis ATCC 33277 containing the erm cassette in place of PGN_1341 & This study \\
\hline PGAGU111 & P. gingivalis PGAGU104 containing tetQ in place of PGN_1888 & This study \\
\hline PGAGU114 & P. gingivalis PGAGU109 containing tetQ in place of PGN_1888 & This study \\
\hline PGAGU115 & P. gingivalis PGAGU109 containing tetQ in place of PGN_0725 & This study \\
\hline PGAGU118 & P. gingivalis PGAGU115 containing cepA in place of PGN_1888 & This study \\
\hline \multicolumn{3}{|l|}{ Plasmids } \\
\hline pVA2198 & $\mathrm{Em}^{\mathrm{R}}$ in E. coli and $P$. gingivalis & Fletcher et al., 1997 \\
\hline pT-COW & $A p^{R}$ and $T c^{R}$ in E. coli, $T c^{R}$ in $P$. gingivalis & Gardner et al., 1996 \\
\hline pCEPA & $\begin{array}{l}\mathrm{Ap}^{\mathrm{R}} \text { in } E . \text { coli and } P \text {. gingivalis; pCR-Blunt II TOPO (Thermo Fisher Scientific) containing cepA with its } \\
\text { native promoter and terminator }\end{array}$ & $\begin{array}{l}\text { Dr. Naito, Nagasaki } \\
\text { University, Japan }\end{array}$ \\
\hline pUC19 & $A p^{R}$, vector for cloning & GE Healthcare \\
\hline pGN1171 & $\begin{array}{l}\mathrm{Cm}^{\mathrm{R}} \text { and } \mathrm{Em}^{\mathrm{R}} \text {, pUC19 derivative containing the erm cassette flanked by upstream and downstream } \\
\text { regions of PGN_1171 }\end{array}$ & This study \\
\hline pKO0725-erm & $\begin{array}{l}A p^{R} \text { and } E m^{R} \text {, pUC19 derivative containing the erm cassette flanked by upstream and downstream } \\
\text { regions of PGN_0725 }\end{array}$ & This study \\
\hline pKO0725-tetQ & $\begin{array}{l}\mathrm{Ap}^{\mathrm{R}} \text { and } \mathrm{Tc}^{\mathrm{R}} \text {, pUC19 derivative containing tetQ flanked by upstream and downstream regions of } \\
\text { PGN_0725 }\end{array}$ & This study \\
\hline pKO1341-erm & $\begin{array}{l}A p^{R} \text { and } E m^{R} \text {, pUC19 derivative containing the erm cassette flanked by upstream and downstream } \\
\text { regions of PGN_1341 }\end{array}$ & This study \\
\hline pKO1888-erm & $\begin{array}{l}\mathrm{Ap}^{\mathrm{R}} \text { and } \mathrm{Em}^{\mathrm{R}} \text {, pUC19 derivative containing the erm cassette flanked by upstream and downstream } \\
\text { regions of PGN_1888 }\end{array}$ & This study \\
\hline pKO1888-tetQ & $\begin{array}{l}\mathrm{Ap}^{\mathrm{R}} \text { and } \mathrm{Tc}^{\mathrm{R}} \text {, pUC19 derivative containing tetQ flanked by upstream and downstream regions of } \\
\text { PGN_1888 }\end{array}$ & This study \\
\hline pKO1888-серА & $\mathrm{Ap}^{\mathrm{R}}$, pUC19 derivative containing cepA flanked by upstream and downstream regions of PGN_1888 & This study \\
\hline pGEX-6P-1 & $A p^{R} ;$ GST fusion expression vector & GE Healthcare \\
\hline pPR0725-GeX & $\mathrm{Ap}^{\mathrm{R}} ;$ pGEX-6P-1 derivative containing PGN_0725 gene & This study \\
\hline pPR1341-GeX & $\mathrm{Ap}^{\mathrm{R}}$; pGEX-6P-1 derivative containing PGN_1341 gene & This study \\
\hline pPR1888-GeX & $\mathrm{Ap}^{\mathrm{R}}$; pGEX-6P-1 derivative containing PGN_1888 gene & This study \\
\hline pPR1171-GeX & $\mathrm{Ap}^{\mathrm{R}} ; \mathrm{pGEX}-6 \mathrm{P}-1$ derivative containing PGN_1171 gene & This study \\
\hline
\end{tabular}

PCR amplification of the specific products across the upstream and downstream insertion boundaries using primers that were designed based on the flanking sequences extraneous to those used for gene targeting.

\section{Preparation of Crude Enzyme Extracts and Recombinant Proteins}

Crude enzyme extracts were obtained from $P$. gingivalis ATCC 33277 and its derivatives grown anaerobically in modified GAM broth to log phase. Harvested cells were washed two times with phosphate-buffered saline (PBS), suspended in PBS containing $0.1 \mathrm{mM} N$ - $\alpha$-tosyl-L-lysine chloromethyl ketone, $0.2 \mathrm{mM}$ phenylmethylsulfonyl fluoride, and $0.1 \mathrm{mM}$ leupeptin (as protease inhibitors), and then lysed by ultrasonication on ice. After ultracentrifugation at $30,000 \times g$ to remove insoluble material, crude enzyme concentrations were determined using the Pierce BCA Protein Assay Kit (Thermo Fisher Scientific, Rockford, IL, USA).
Recombinant PGN_0725, PGN_1341, PGN_1888, and PGN_1171 proteins were obtained using the expression vector pGEX-6P-1 (GE Healthcare Japan), as described previously (Yoshida et al., 2015). Coding sequences were PCR-amplified from the genomic DNA of $P$. gingivalis ATCC 33277 using primers listed in Supplementary Table S1. The amplicons were ligated into pGEX-6P-1 vector, and the resulting plasmids were verified by sequencing and are listed in Table 1. Protein concentrations were determined, as described previously (Pace et al., 1995), and protein purity was assessed by SDS-PAGE.

\section{Colorimetric Assay}

CoA transferase activity in crude enzyme extracts or purified recombinant proteins was measured by determining the concentrations of acetyl-CoA, a reaction byproduct, with citrate synthase assay (Scherf and Buckel, 1991). Reaction mixtures $(40 \mu \mathrm{l})$ consisted of $40 \mathrm{mM}$ potassium phosphate buffer $(\mathrm{pH}$ 8.0), $200 \mathrm{mM}$ sodium acetate, and $1 \mathrm{mM}$ CoA derivatives (propionyl-CoA, butyryl-CoA, crotonyl-CoA, acetoacetyl-CoA, 
succinyl-CoA, or 3-hydroxybutyryl-CoA). After pre-warming, reactions were initiated by the addition of enzyme $(25 \mu \mathrm{g} / \mathrm{ml}$ crude enzyme extracts, $125 \mathrm{ng} / \mathrm{ml}$ PGN_0725, $1.25 \mu \mathrm{g} / \mathrm{ml}$

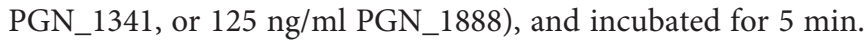
The reactions were terminated by the addition of $10 \mu \mathrm{l}$ of $4.5 \%$ trichloroacetic acid. To neutralize the solution, $25 \mu \mathrm{l}$ of $400 \mathrm{mM}$ potassium phosphate buffer ( $\mathrm{pH}$ 8.0) was added. After neutralization, assay mixtures $(25 \mu \mathrm{l})$ containing $4 \mathrm{mM}$

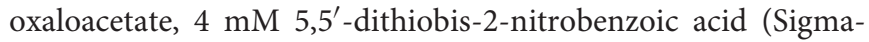
Aldrich, St. Louis, MO, USA), and $36.8 \mu \mathrm{g} / \mathrm{ml}$ citrate synthase (Sigma-Aldrich) were added to the reaction mixtures for acetyl$\mathrm{CoA}$ determinations. After incubation at $37^{\circ} \mathrm{C}$ for $30 \mathrm{~min}$, the samples were examined spectrophotometrically at $412 \mathrm{~nm}$ $\left(A_{412}\right)$. Acetyl-CoA concentrations were calculated using a standard curve. In addition to the reaction conditions described above, varying concentrations of sodium acetate (20-250 mM) and either butyryl-CoA $(0.5-5.0 \mathrm{mM})$ or propionyl-CoA $(0.2-$ $3.0 \mathrm{mM}$ ) were used to determine the kinetic parameters of each recombinant protein. These parameters were computed from Lineweaver-Burk transformation $\left(V^{-1}\right.$ vs. $\left.S^{-1}\right)$ of the MichaelisMenten equation. The $k_{\text {cat }}$ values were calculated from $V_{\max }$ and molecular weights of the proteins. Data were obtained from three independent experiments.

Recombinant protein CoA transferase activity with 4hydroxybutyrate and acetyl-CoA was determined using PGN_0724, a succinate semialdehyde reductase producing 4-hydroxybutyrate from succinate semialdehyde (Yoshida et al., 2015), since 4-hydroxybutyrate is not commercially available. Each reaction mixture $(100 \mu \mathrm{l})$ contained $40 \mathrm{mM}$ potassium phosphate buffer ( $\mathrm{pH} 8.0$ ), $0.5 \mathrm{mM}$ succinate semialdehyde, $0.5 \mathrm{mM}$ NADH, $0.5 \mathrm{mM}$ acetyl-CoA, $1 \mathrm{mM} \mathrm{MnCl}_{2}$, and $1 \mu \mathrm{g} / \mathrm{ml}$ recombinant protein (PGN_0724, PGN_0725, PGN_1341, and/or PGN_1888). After incubation for $60 \mathrm{~min}$ at $37^{\circ} \mathrm{C}$, the concentration of unconsumed $\mathrm{NADH}$ was determined spectrophotometrically at $A_{340}$, using a standard curve. The concentration of unconsumed acetyl-CoA was determined using a citrate synthase assay, as described above.

\section{Gas Chromatography/Mass Spectrometry analysis}

SCFAs in the reaction mixtures and culture supernatants were evaluated by gas chromatography/mass spectrometry (GC-MS) with a ZB-FFAP column (length, $30 \mathrm{~m}$; diameter, $0.32 \mathrm{~mm}$; film thickness, $0.25 \mu \mathrm{m}$; Phenomenex Inc., Torrance, CA, USA), as described previously (Yoshida et al., 2015). Briefly, the injection port temperature was set at $150^{\circ} \mathrm{C}$. Helium was used as the carrier gas, with a linear velocity of $50 \mathrm{~cm} / \mathrm{s}$. The oven temperature was held at $80^{\circ} \mathrm{C}$ for $1 \mathrm{~min}$, increased to $135^{\circ} \mathrm{C}$ at a rate of $10^{\circ} \mathrm{C} / \mathrm{min}$, further increased to a final temperature of $230^{\circ} \mathrm{C}$ at a rate of $30^{\circ} \mathrm{C} / \mathrm{min}$, and held for $6 \mathrm{~min}$. For MS, the ionization source temperature was $200^{\circ} \mathrm{C}$. The volume injected was $1 \mu \mathrm{l}$ in splitless mode. To quantify the concentrations of individual SCFAs, experiments were performed in selected ion monitoring mode. Each enzyme reaction mixture $(100 \mu \mathrm{l})$, containing $40 \mathrm{mM}$ potassium phosphate buffer $(\mathrm{pH} 8.0), 500 \mathrm{ng} / \mathrm{ml}$ recombinant protein, $200 \mathrm{mM}$ sodium acetate, and either $1 \mathrm{mM}$ butyryl-CoA or $1 \mathrm{mM}$ propionyl-CoA, was incubated at $37^{\circ} \mathrm{C}$ for $60 \mathrm{~min}$. The bacterial supernatant samples were prepared by diluting the bacterial cultures with fresh modified GAM broth to optical density at $600 \mathrm{~nm}\left(\mathrm{OD}_{600}\right)=0.375 \pm 0.025\left(1.5 \times 10^{5} \mathrm{CFU} / \mu \mathrm{l}\right)$ to normalize cell concentration. Diluted bacterial cultures were immediately centrifuged to remove bacterial cells. Aliquots $(100 \mu \mathrm{l})$ of enzyme reaction mixtures or supernatants were added to $500 \mu \mathrm{l}$ of acetone. After incubation at $-20^{\circ} \mathrm{C}$ for $2 \mathrm{~h}$, the samples were centrifuged to remove proteins.

\section{Statistical Analysis}

Differences between groups were analyzed by one-way analysis of variance, followed by the Student-Newman-Keuls multiplecomparisons test. Differences were considered significant when $P<0.01$.

\section{RESULTS}

\section{Identification of PGN_0725, PGN_1341, and PGN_1888 Proteins as Butyryl-CoA:Acetate CoA Transferases}

Although PGN_1171 has been previously annotated as a butyryl-CoA:acetate CoA transferase of $P$. gingivalis ATCC 33277 (Nelson et al., 2003; Hendrickson et al., 2009), the deduced PGN_1171 amino acid sequence shared no more than 20 and 27\% identity with R. hominis RHOM_13820 protein and Clostridium aminobutyricum AbfT protein, respectively, both of which were experimentally shown to function as butyryl-CoA:acetate CoA transferases (Scherf and Buckel, 1991; Charrier et al., 2006). In addition, PGN_1171 (220 aa) was much shorter than RHOM_13820 (446 aa) and AbfT (438 aa). A database search revealed greater RHOM_13820 amino acid identity with PGN_0725 (38.5\%), PGN_1341 (23.7\%), and PGN_1888 (36.4\%) proteins, all of which have been annotated as putative CoA transferases in $P$. gingivalis ATCC 33277 (Naito et al., 2008), than PGN_1171. Moreover, the lengths of PGN_0725 (431 aa), PGN_1341 (498 aa), and PGN_1888 (431 aa) proteins were similar to RHOM_13820 and AbfT.

To evaluate the function of PGN_1171, PGN_0725, PGN_1341, and PGN_1888 proteins, eight deletion strains, including double and triple mutants, were constructed using erythromycin, tetracycline, and ampicillin resistance genes (Table 1). Integration of the resistance genes at the expected chromosomal locations in the resulting mutant strains was verified by PCR (Supplementary Figure S1).

Butyrate and acetyl-CoA are produced from butyryl-CoA and acetate in the last step of butyrate production (Figure 1). Butyryl-CoA:acetate CoA transferase activity of crude enzyme extracts was determined by measuring the production of acetylCoA from butyryl-CoA and sodium acetate. The initial velocity of acetyl-CoA production by PGAGU101 (PGN_1171::erm) crude enzyme extracts was not significantly different from that of the wild type (Figure 2A), indicating that PGN_1171 has no detectable butyryl-CoA:acetate CoA transferase activity. By 


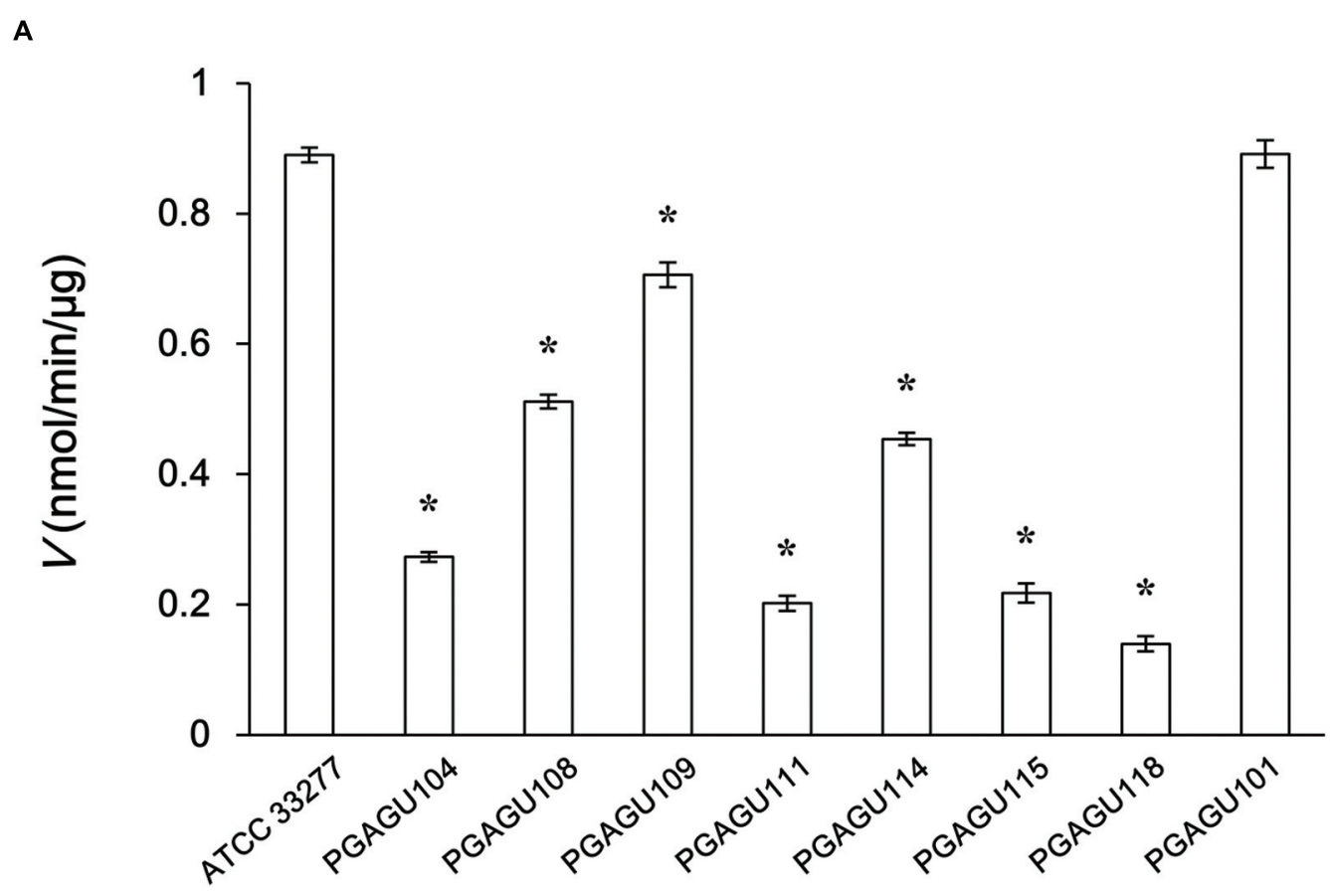

B

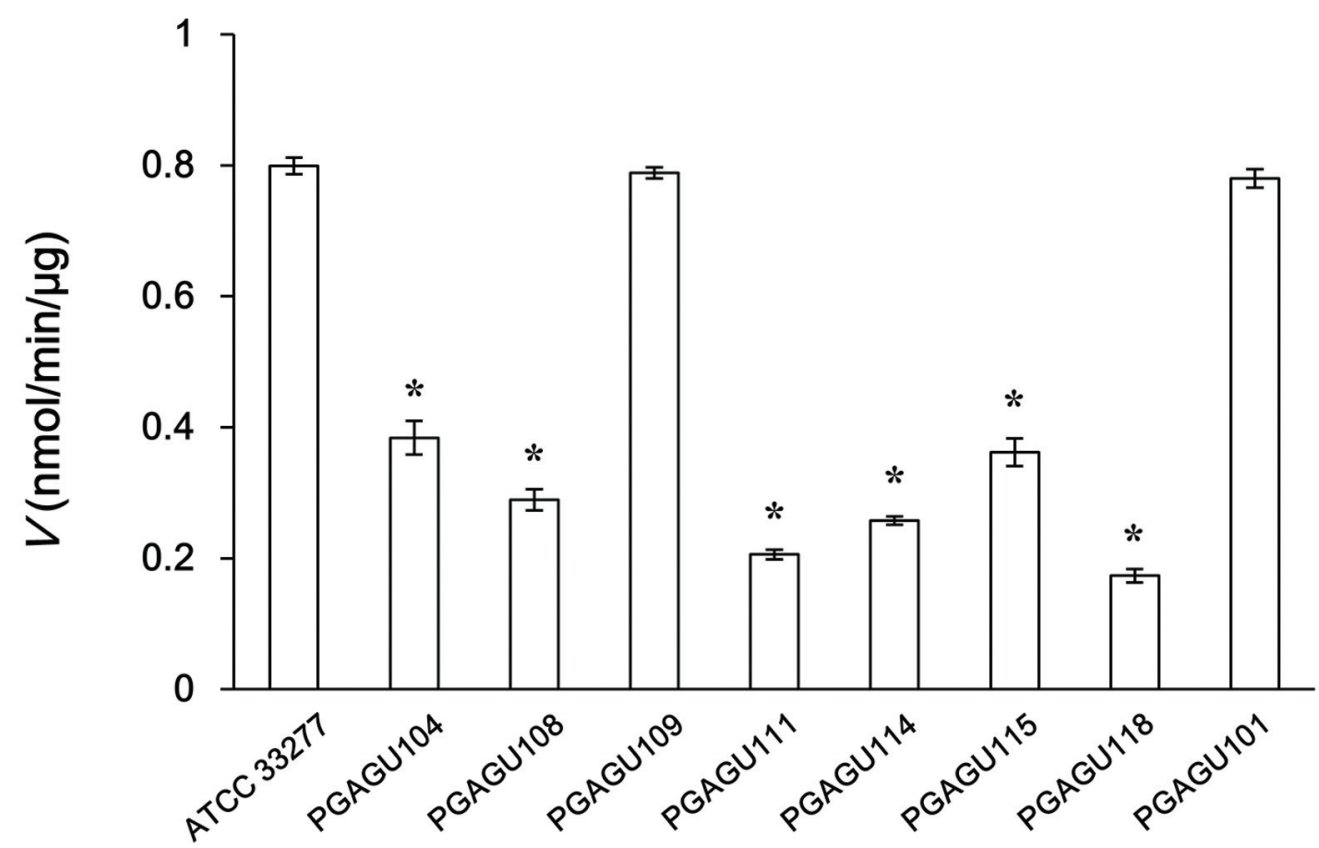

FIGURE 2 | Initial velocities of crude enzyme extracts of $P$. gingivalis ATCC 33277 and its mutant strains for butyryl-CoA (A) and propionyl-CoA (B). The reaction mixtures, containing $25 \mu \mathrm{g} / \mathrm{ml}$ crude enzyme extracts, $200 \mathrm{mM}$ sodium acetate, and $1 \mathrm{mM}$ butyryl-CoA or propionyl-CoA, were incubated for 5 min. The concentration of $\mathrm{CoA}$, a reaction byproduct, was measured. Data represent the mean \pm standard deviation $(n=3)$. Asterisks indicate significant differences compared with the wild type $(P<0.01)$.

contrast, disruption of PGN_0725, PGN_1341, or PGN_1888 resulted in a significant decrease in the reaction velocity, suggesting that all the encoded proteins possess the butyrylCoA:acetate CoA transferase activity.
Likewise, propionate and acetyl-CoA were produced from propionyl-CoA and acetate (Figure 1). The abilities of crude enzyme extracts of PGAGU101, PGAGU109 (PGN_1341::erm), and the wild type strain to form acetyl-CoA from propionyl-CoA 
and acetate were not significantly different (Figure 2B). The initial velocities of PGAGU104 (PGN_0725::erm) and PGAGU108 (PGN_1888::erm) crude enzyme extracts were significantly lower than that of the wild type. These findings demonstrated that PGN_0725 and PGN_1888, but not PGN_1171 and PGN_1341, possess the propionyl-CoA:acetate CoA transferase activity.

\section{Enzymatic Characterization of Recombinant PGN_0725, PGN_1341, and PGN_1888 Proteins}

To characterize PGN_0725, PGN_1341, PGN_1888, and PGN_1171 protein functions, each corresponding gene was expressed in E. coli to produce recombinant proteins. Molecular masses of the denatured PGN_0725, PGN_1341, PGN_1888, and PGN_1171 polypeptides agreed well with the respective predicted molecular masses $(47.4,54.7,47.8$, and $23.2 \mathrm{kDa}$, respectively; Figure 3).

GC-MS analysis demonstrated that incubation of butyryl-CoA and sodium acetate with any of the recombinant PGN_0725, PGN_1341, and PGN_1888 proteins led to the production of butyrate (Figure 4). Propionate was detected in reaction mixtures containing propionyl-CoA, sodium acetate, and either recombinant PGN_0725 or PGN_1888, but not PGN_1341. As expected, incubation of the recombinant PGN_1171 protein with butyryl-CoA or propionyl-CoA in the presence of sodium acetate resulted in no detectable production of butyrate or propionate, respectively (Figure 4).

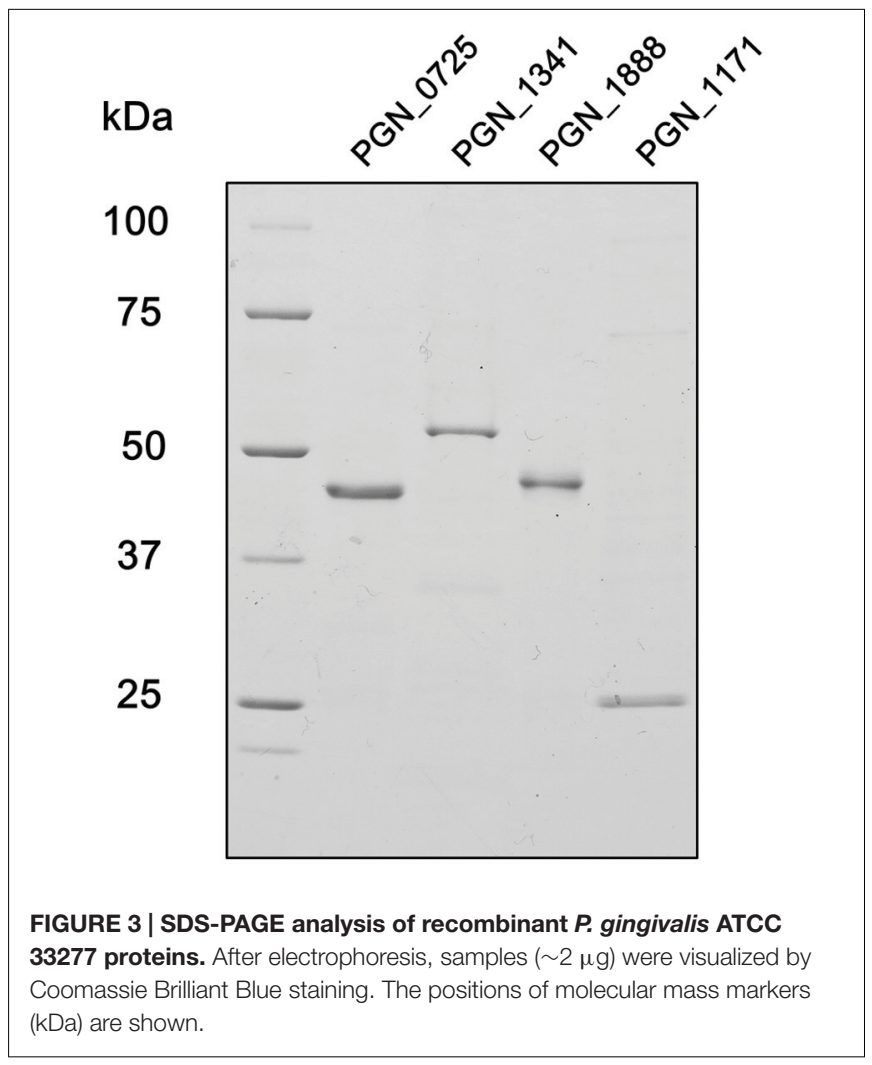

We also investigated the kinetic parameters of recombinant PGN_0725, PGN_1341, and PGN_1888 using a colorimetric assay. Initial velocities were determined at either fixed sodium acetate concentrations at different butyryl-CoA concentrations, or fixed butyryl-CoA concentrations at different sodium acetate concentrations. Lineweaver-Burk (double reciprocal) plots were then constructed (Figure 5). Line series intersecting to the left of $y$-axes $\left(V^{-1}\right)$ suggested that PGN_0725, PGN_1341, and PGN_1888 proteins act via a ternary-complex kinetic mechanism. $K_{\mathrm{m}}$ and $V_{\max }$ values were estimated from secondary plots (Figures 5B,C; Table 2). In addition, $k_{\text {cat }}$ values were calculated from enzyme concentrations in the reaction mixtures. Kinetic properties of the recombinant PGN_0725 and PGN_1888 proteins were also determined by analyzing acetyl-CoA production from sodium acetate and propionyl-CoA (Table 3). These reactions also follow the ternary-complex mechanism (Figure 6).

\section{Substrate Specificity of Recombinant PGN_0725, PGN_1341, and PGN_1888 Proteins}

To investigate substrate specificity of the recombinant proteins, four CoA derivatives (crotonyl-CoA, acetoacetyl-CoA, succinylCoA, and 3-hydroxybutyryl-CoA) were evaluated as substrates, in addition to butyryl-CoA and propionyl-CoA (Supplementary Figure S2). When the CoA derivatives tested were incubated with PGN_0725, PGN_1341, or PGN_1888 in the presence of sodium acetate, no significant production of acetyl-CoA was detected, suggesting that crotonyl-CoA, acetoacetyl-CoA, succinyl-CoA, and 3-hydroxybutyryl-CoA were not used as a substrate by these enzymes.

Next, sodium butyrate and sodium propionate (instead of sodium acetate) were tested as enzyme substrates in the presence of propionyl-CoA and butyryl-CoA, respectively. GC-MS analysis revealed that the incubation of a sodium butyrate/propionyl-CoA pair or sodium propionate/butyryl-CoA pair with PGN_0725, PGN_1341, or PGN_1888 resulted in no detectable production of propionate or butyrate (data not shown). These findings suggested that the three CoA transferases utilize no SCFA substrates other than acetate.

Since PGN_0725 was annotated as a 4-hydroxybutyrate CoA transferase (Nelson et al., 2003; Naito et al., 2008; Hendrickson et al., 2009), an enzyme catalyzing the formation of 4hydroxybutyryl-CoA from 4-hydroxybutyrate and acetyl-CoA (Figure 1), we examined the 4-hydroxybutyrate CoA transferase activity of recombinant PGN_0725 (Supplementary Figure S3). In this assay, the recombinant PGN_0724 that produces 4hydroxybutyrate from succinate semialdehyde was used (Yoshida et al., 2015), because the 4-hydroxybutyrate is not commercially available. When recombinant PGN_0724 was incubated with $\mathrm{NADH}$ and succinate semialdehyde, NADH was consumed, indicating 4-hydroxybutyrate production. However, incubation of a mix of recombinant PGN_0724 and PGN_0725 proteins with the reaction mixture resulted in no significant acetyl-CoA consumption, suggesting that PGN_0725 does not produce 4hydroxybutyryl-CoA from 4-hydroxybutyrate and acetyl-CoA. 


\section{A}

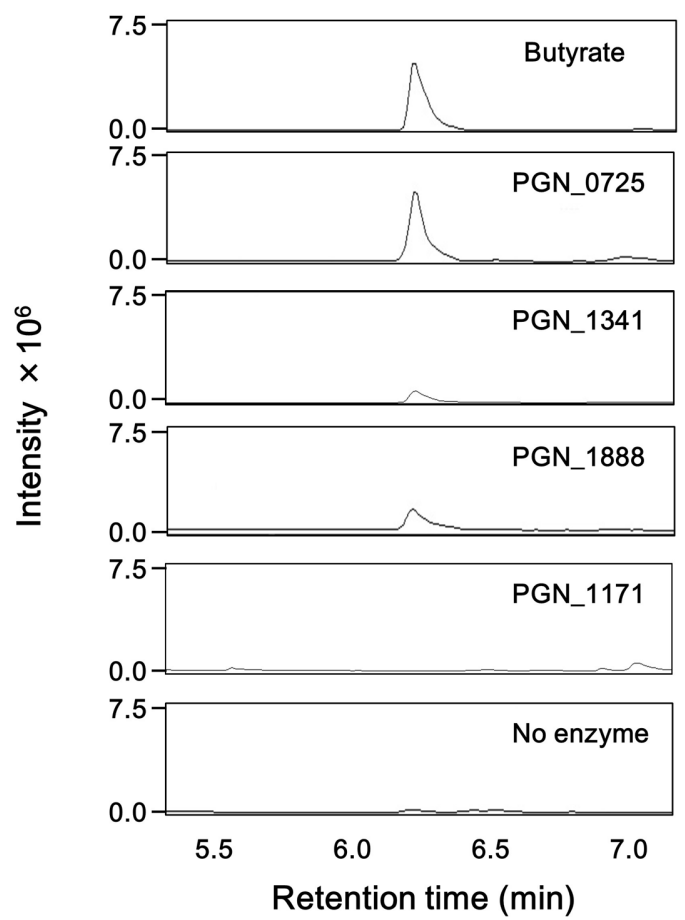

B

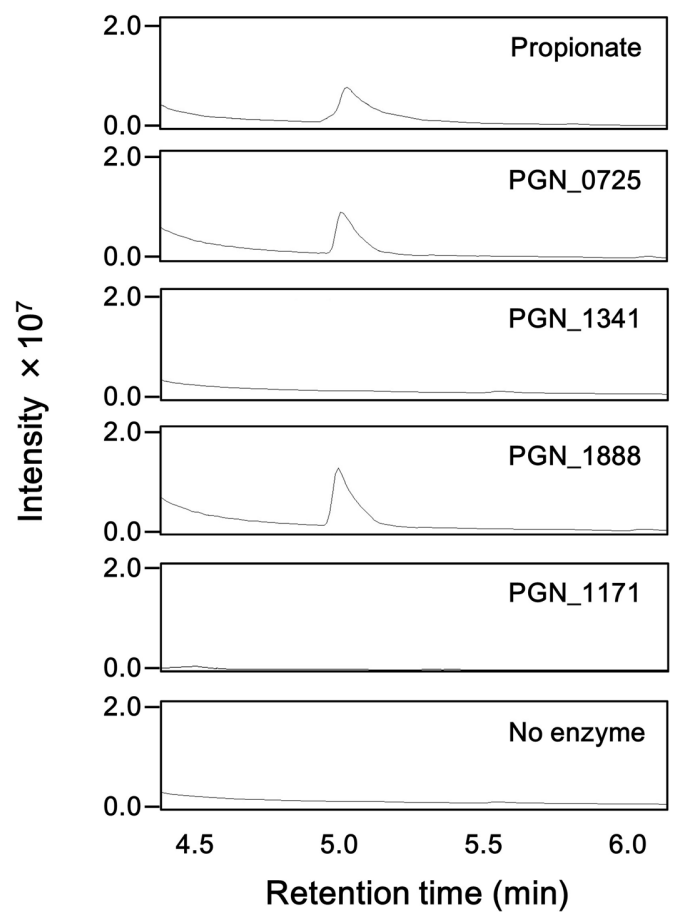

FIGURE 4 | GC-MS chromatograms of butyrate and propionate in reaction mixtures. Total ion chromatogram of butyrate (A) and propionate (B) is shown. The mass spectra of each sample agree well with those of the corresponding standard. The reaction mixtures, containing $200 \mathrm{mM}$ sodium acetate and either $1 \mathrm{mM}$ butyryl-CoA or $1 \mathrm{mM}$ propionyl-CoA, with recombinant PGN_0725, PGN_1341, PGN_1888, or PGN_1171 proteins, were incubated for 1 h. After the proteins were removed by acetone precipitation treatment, aqueous phase aliquot $(1 \mu \mathrm{l})$ was analyzed.

Incubation of either recombinant PGN_1341 or PGN_1888 (instead of PGN_0725) in the reaction mixture did not result in acetyl-CoA consumption (data not shown). These findings suggested that PGN_0725, PGN_1341, and PGN_1888 did not function as 4-hydroxybutyrate CoA transferases.

\section{Production of SCFAs by $P$. gingivalis ATCC 33277 and Mutant Strains}

PGAGU108 grew as fast as the wild type, as determined by $\mathrm{OD}_{600}$ measurements of the cell cultures (Figure 7). By contrast, the growth rates of other mutant strains were obviously slower than that of the wild type, as were culture turbidities in the stationary phase. This suggested that the intermediates and end products of the butyrate, propionate, and related molecule biosynthetic pathways might be important for the metabolism of this microorganism.

To evaluate the contribution of PGN_0725, PGN_1341, and PGN_1888 to SCFA production, SCFA concentrations in stationary phase bacterial cultures were quantified using GC-MS. The $\mathrm{OD}_{600}$ of each culture was adjusted to $0.375 \pm 0.025$ to normalize cell concentrations. This conversion allowed us to compare the production of SCFAs per cell number in the wild type and mutant strains (Figure 8). Butyrate concentrations in culture media of all the mutant strains were significantly lower than that of the wild type $(P<0.01)$. Butyrate concentrations in the culture supernatants of PGAGU104, PGAGU111 (PGN_0725::erm PGN_1888::tetQ), PGAGU115 (PGN_0725::tetQPGN_1341::erm), and PGAGU118 (PGN_0725::tetQ PGN_1341::erm PGN_1888::cepA), all of which lacked the PGN_0725 gene, were significantly lower, not only than that of the wild type, but also than those of other mutants. Likewise, propionate concentrations in culture supernatants of PGAGU108, PGAGU111, PGAGU114 (PGN_1341::erm PGN_1888::tetQ), and PGAGU118, all of which lacked the PGN_1888 gene, were significantly lower than those of other strains. Deletion of PGN_0725, PGN_1341, or PGN_1888 resulted in a drastic decrease in isobutyrate and isovalerate concentrations in culture supernatants (Figure 8). Interestingly, the triple mutant, PGAGU118, still released butyrate, propionate, isobutyrate, and isovalerate into the culture supernatant (Figure 8).

\section{DISCUSSION}

In the current study, we identified and characterized three CoA transferases, PGN_0725, PGN_1341, and PGN_1888, by a homology search with CoA transferase in $R$. hominis (Charrier et al., 2006; Travis et al., 2015). All the proteins 


\section{PGN_0725}
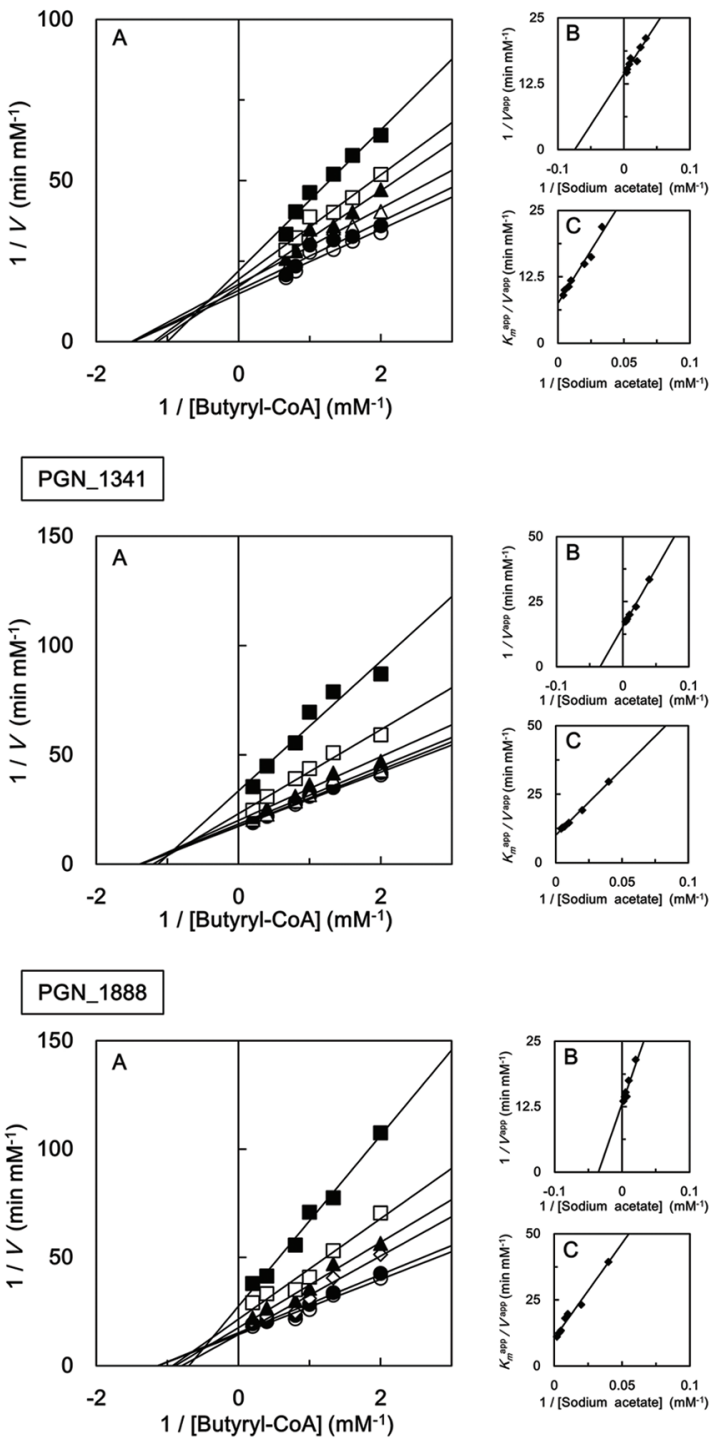

FIGURE 5 | Steady-state kinetic analysis of butyryl-CoA:acetate CoA transferase activities of recombinant PGN_0725, PGN_1341, and PGN_1888 proteins. (A) Double reciprocal plots of the initial velocities of acetyl-CoA and butyrate formation from butyryl-CoA and sodium acetate catalyzed by purified recombinant enzymes. Different butyryl-CoA concentrations $(0.5-5 \mathrm{mM})$ were assayed at fixed sodium acetate concentrations ( $25 \mathrm{mM}$, filled squares; $50 \mathrm{mM}$, open squares; $100 \mathrm{mM}$, filled triangles; $125 \mathrm{mM}$, open triangles; $200 \mathrm{mM}$, filled circles; or $250 \mathrm{mM}$, open circles). (B) Secondary plots of $y$ intercepts (velocity reciprocals) vs. sodium acetate concentrations. (C) Secondary plots of the reciprocal slopes from panel (A) vs. sodium acetate concentration. Data represent the mean \pm standard deviation $(n=3)$

catalyze the production of butyrate and acetyl-CoA from butyryl-CoA and acetate in the butyrate synthesis pathway of P. gingivalis. In addition, PGN_0725 and PGN_1888 proteins also produced propionate and acetyl-CoA from propionyl$\mathrm{CoA}$ and acetate. Despite previous annotation of PGN_1171
TABLE 2 | Kinetic properties of recombinant PGN_0725, PGN_1341, and PGN_1888 proteins for butyryl-CoA and sodium acetate.

\begin{tabular}{lrrc}
\hline & PGN_0725 & PGN_1341 & PGN_1888 \\
\hline $\boldsymbol{K}_{\mathbf{m}}$ & & & \\
Butyryl-CoA $(\mu \mathrm{M})$ & $520 \pm 10$ & $610 \pm 40$ & $920 \pm 70$ \\
Sodium acetate $(\mathrm{mM})$ & $16 \pm 1.8$ & $26 \pm 2.8$ & $33 \pm 5.3$ \\
$V_{\max }\left(\mu \mathrm{M}\right.$ min $\left.^{-1}\right)$ & $71 \pm 0.5$ & $65 \pm 0.8$ & $80 \pm 3.3$ \\
$k_{\text {cat }}\left(\mathrm{s}^{-1}\right)$ & $560 \pm 4.1$ & $24 \pm 0.3$ & $254 \pm 10$ \\
\hline
\end{tabular}

TABLE 3 | Kinetic properties of recombinant PGN_0725 and PGN_1888 proteins for propionyl-CoA and sodium acetate.

\begin{tabular}{lcc}
\hline & PGN_0725 & PGN_1888 \\
\hline $\boldsymbol{K}_{\mathbf{m}}$ & & \\
Propionyl-CoA $(\mu \mathrm{M})$ & $108 \pm 47$ & $23 \pm 4.4$ \\
Sodium acetate $(\mathrm{mM})$ & $92 \pm 7.9$ & $89 \pm 23$ \\
$V_{\max }\left(\mu \mathrm{M}\right.$ min $\left.^{-1}\right)$ & $67.5 \pm 4.0$ & $86 \pm 30$ \\
$k_{\text {cat }}\left(\mathrm{s}^{-1}\right)$ & $533 \pm 31$ & $1374 \pm 477$ \\
\hline
\end{tabular}

as a protein responsible for this reaction to produce butyrate (Nelson et al., 2003; Hendrickson et al., 2009), the protein had no detectable butyryl-CoA:acetate CoA transferase or propionyl-CoA:acetate CoA transferase activity (Figure 2). The deduced amino acid sequence of PGN_1171 shared 46 and $24 \%$ identity with PcaJ from Pseudomonas putida (Parales and Harwood, 1993) and Sinorhizobium meliloti (MacLean et al., 2006), respectively. The PcaJ protein comprises one of the two subunits of succinyl-CoA/ $\beta$-ketoadipate $\mathrm{CoA}$ transferase that catalyze the production of $\beta$-ketoadipyl-CoA from $\beta$-ketoadipate and succinyl-CoA. PGN_1171 might be a subunit of a heterodimer functioning as a CoA transferase for CoA derivatives other than butyryl-CoA and propionylCoA. However, the function of PGN_1171 protein remains unknown.

Several mutant strains were constructed to examine the role of PGN_0725, PGN_1341, and PGN_1888 (Table 1; Supplementary Figure S1). Butyrate concentration in culture supernatants of PGAGU104, PGAGU111, PGAGU115, and PGAGU118 decreased by 85.7, 91.6, 93.1, and 94.1\%, respectively, compared with that of the wild type strain (Figure 8). Notably, butyrate concentrations in culture supernatants of these mutants, all of which lacked PGN_0725 (Table 1), were significantly lower, not only than that of the wild type, but also other mutants. Similarly, butyryl-CoA:acetate CoA transferase activities in crude enzyme extracts of PGN_0725-lacking strains were lower than those of other strains (Figure 2). Furthermore, of the recombinant proteins tested, PGN_0725 displayed the highest butyryl-CoA:acetate CoA transferase activity (Table 2). Taken together, the PGN_0725 protein contributes the most to butyrate production in $P$. gingivalis. Likewise, the findings summarized in Figures 2 and 8, and Table 3, demonstrate that PGN_1888 is a CoA transferase contributing the most to the production of propionate. Deletion of PGN_0725, PGN_1341, or PGN_1888 resulted in low concentrations of isobutyrate and isovalerate in culture supernatants (Figure 8). 

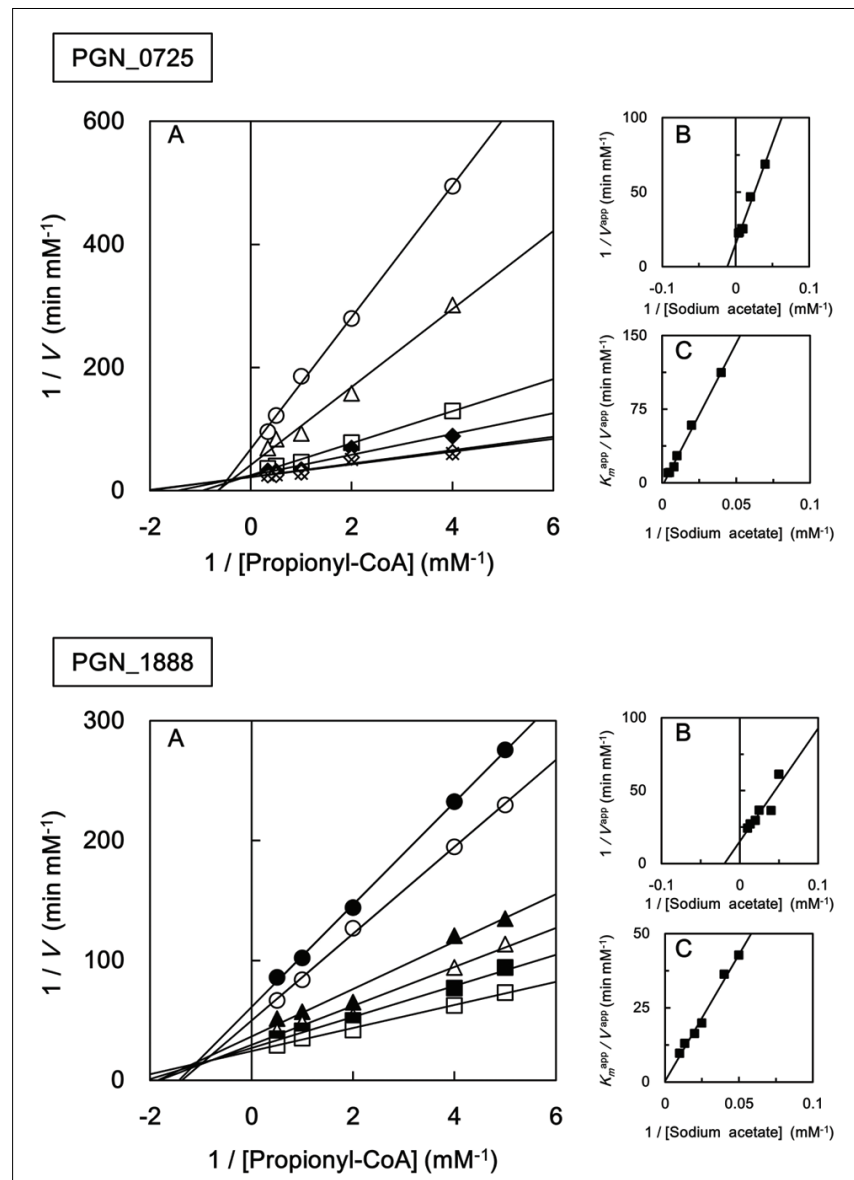

FIGURE 6 | Steady-state kinetic analysis of propionyl-CoA:acetate CoA transferase activities of recombinant PGN_0725 and PGN_1888 proteins. (A) Double reciprocal plots of the initial velocities of acetyl-CoA and propionate formation from propionyl-CoA and sodium acetate catalyzed by purified recombinant enzymes. Different concentrations of propionyl-CoA (0.2-3 mM) were assayed at fixed sodium acetate concentrations ( $20 \mathrm{mM}$, filled circles; $25 \mathrm{mM}$, open circles; $40 \mathrm{mM}$, filled triangles; $50 \mathrm{mM}$, open triangles; $75 \mathrm{mM}$, filled squares; $100 \mathrm{mM}$, open squares; $125 \mathrm{mM}$, filled diamonds; 200 mM, open diamonds; and 250 mM, crosses). (B) Secondary plots of $y$ intercepts (velocity reciprocals) vs. sodium acetate concentrations. (C) Secondary plots of the reciprocal slopes from panel (A) vs. sodium acetate concentrations. Data represent the mean \pm standard deviation $(n=3)$.

These observations suggested that the isobutyrate and isovalerate synthetic pathways might share their intermediates with the butyrate synthetic pathway in $P$. gingivalis. Synthetic pathways of those molecules remain to be elucidated. It is also of interest that the CoA transferase activity in crude enzyme extracts of the triple mutant strain (PGAGU118) was $\sim 20 \%$ that of the wild type, suggesting that $P$. gingivalis harbors additional CoA transferase(s) other than PGN_0725, PGN_1341, and PGN_1888. CoA transferase(s) with relatively broad substrate specificity may be partially involved in the formation of butyrate and propionate from butyryl-CoA and propionylCoA, respectively. Further studies are necessary to precisely understand the production of butyrate and propionate in bacteria.

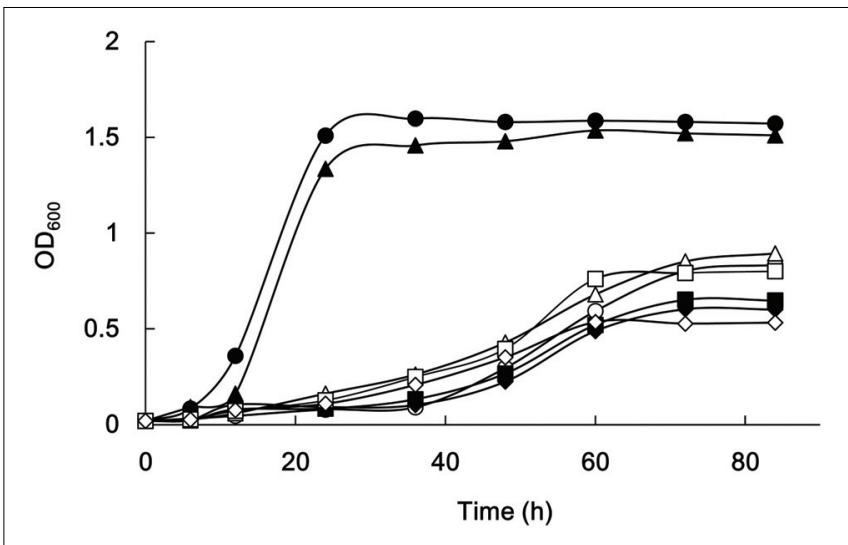

FIGURE 7 | Growth of $\boldsymbol{P}$ gingivalis strains. P. gingivalis ATCC 33277 (filled circles), PAGU104 (open circles), PAGU108 (filled triangles), PAGU109 (open triangles), PAGU111 (filled squares), PAGU114 (open squares), PAGU115 (filled diamonds), and PAGU118 (open diamonds) were assessed after 6, 12, $24,36,48,60,72$, and $84 \mathrm{~h}$. Representative data for at least two independent experiments are shown.

PGN_0725 was annotated as a 4-hydroxybutyrate CoA transferase (Nelson et al., 2003; Naito et al., 2008; Hendrickson et al., 2009). Indeed, the amino acid identity shared by PGN_0725 and C. aminobutyricum AbfT proteins, the latter of which was experimentally verified as a 4-hydroxybutyrate CoA transferase (Scherf and Buckel, 1991; Gerhardt et al., 2000), was higher than that shared by PGN_0725 and $R$. hominis RHOM_13820 protein, which presumably does not function as a 4-hydroxybutyrate CoA transferase (Charrier et al., 2006). However, no 4-hydroxybutyrate CoA transferase activity was detected in PGN_0725 recombinant protein (Supplementary Figure S3), similarly to the recombinant PGN_1341 and PGN_1888 proteins. Our findings also suggest that an additional CoA transferase(s) possibly exists in $P$. gingivalis. This study demonstrated that PGN_1341 functions as a CoA transferase producing butyrate from butyryl-CoA (Figure 4). However, considering that the butyryl-CoA:acetate CoA transferase activity of PGN_1341 is much lower than that of PGN_0725, the primary role of $\mathrm{PGN}$ _1341 in $P$. gingivalis remains unknown. Although PGN_1341 is not responsible for propionate production from propionyl-CoA in this bacterium, replacement of its gene with the $\mathrm{erm}$ cassette resulted in a reduction of propionate levels in culture supernatants (Figure 8). These findings suggest that PGN_1341 might primarily function as a CoA transferase involved in the butyrate and propionate biosynthetic pathways.

The $k_{\text {cat }}$ values of $R$. hominis RHOM_13820 (Charrier et al., 2006) and C. aminobutyricum AbfT (Gerhardt et al., 2000) for butyryl-CoA (91.5 and $119 \mathrm{~s}^{-1}$, respectively) were higher than that of PGN_1341, but lower than those of PGN_0725 and PGN_1888. By contrast, $k_{\text {cat }}$ values of RHOM_13820 and AbfT for propionyl-CoA (41.7 and $120 \mathrm{~s}^{-1}$, respectively) were also much lower than those of PGN_0725 and PGN_1888 proteins. PGN_0725, PGN_1341, and PGN_1888 proteins catalyzed transferase reactions via a ternary-complex kinetic mechanism, 

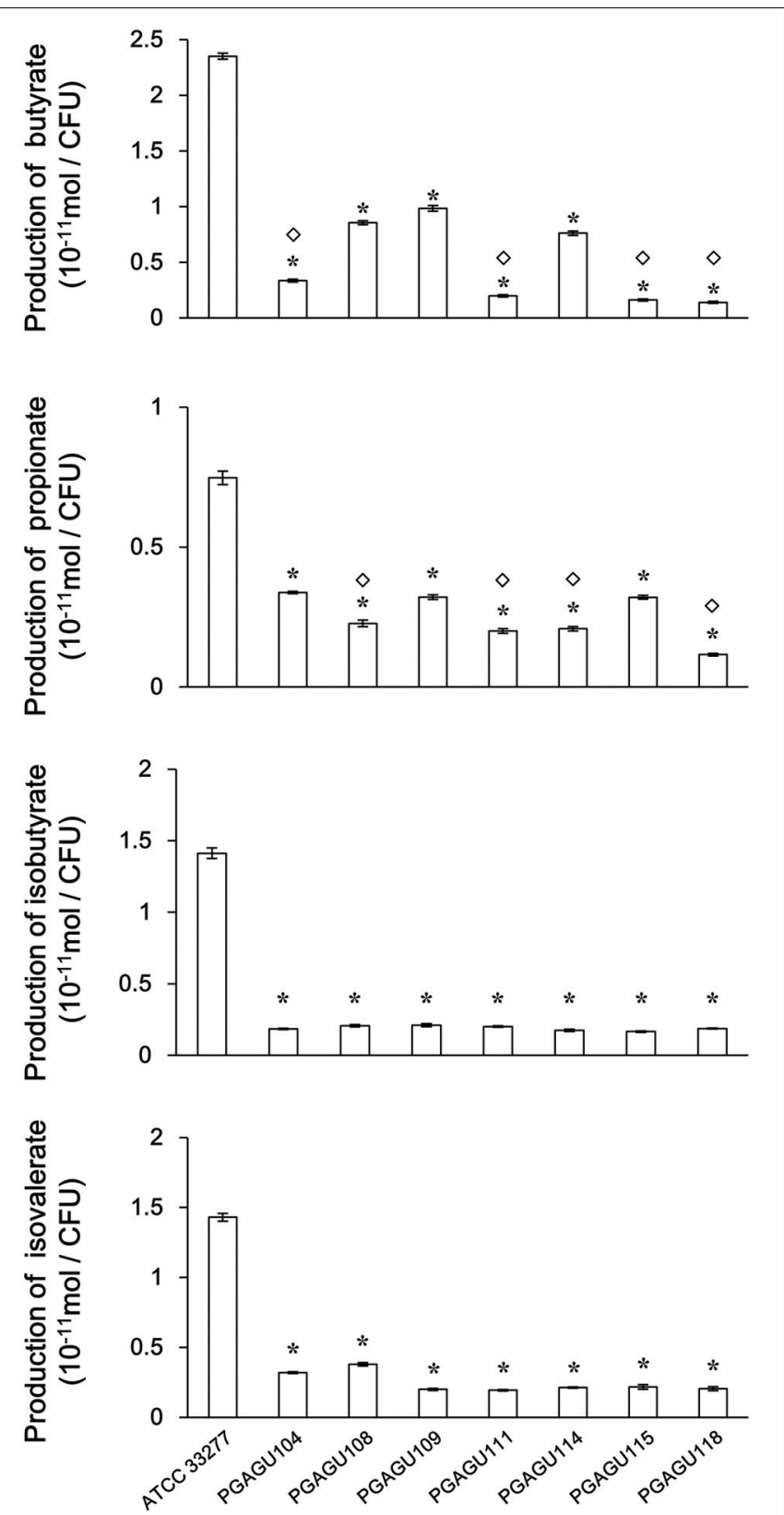

FIGURE 8 | SCFA concentrations in culture supernatants of $\boldsymbol{P}$. gingivalis ATCC $\mathbf{3 3 2 7 7}$ and mutant strains. The supernatants were obtained by centrifugation of bacterial cultures $\left(\mathrm{OD}_{600} 0.375 \pm 0.025\right)$ and diluted 1:6. Data represent the mean \pm standard deviation $(n \geq 3)$. Asterisks indicate significant differences compared with the wild type $(P<0.01)$.

Diamonds indicate significant differences compared with each no diamond strain $(P<0.01)$.

whereas RHOM_13820 protein was reported to catalyze a transferase reaction via a ping-pong bi-bi mechanism (Charrier et al., 2006). Thus, PGN_0725, PGN_1341, and PGN_1888 were different from AbfT in terms of substrate specificity and different from RHOM_13820 in terms of kinetic mechanism. Clarification of the precise enzymatic mechanisms underlying enzyme binding of the butyryl-CoA or propionyl-CoA substrates might require crystallographic analyses.

The concentrations of propionate and butyrate in the gingival crevices are associated significantly with clinical measures of the periodontal diseases' severity and inflammation (Niederman et al., 1997). Nevertheless, a database search analysis showed that the orthologs of PGN_0725, PGN_1341, and PGN_1888 are only in limited species of anaerobic periodontopathogens, including Tannerella forsythia and Fusobacterium nucleatum, but not in Treponema denticola and Prevotella intermedia, both of which are representative periodontopathogens (Socransky and Haffajee, 2002). The relationship between the clinical severity and the proportion of the SCFA-producing bacteria in the gingival crevices has to be investigated to understand the effect of SCFAs in the gingival crevices on the initiation and progression of periodontitis.

\section{CONCLUSION}

This study addressed the function of three genes, and the proteins that they encode, as CoA transferases associated with SCFAs production in P. gingivalis. PGN_0725, PGN_1341, and PGN_1888 were involved in the last step of butyrate production, where butyrate and acetyl-CoA were produced from acetate and butyryl-CoA. PGN_0725 and PGN_1888 also catalyze the transfer of CoA moieties of propionyl-CoA to acetate, to produce propionate. Culture supernatant of the triple deletion mutant still contained a small amount of butyrate and propionate, suggesting the existence of additional CoA transferase(s). Further studies of molecules associated with the butyrate production pathway are currently underway in our laboratory.

\section{AUTHOR CONTRIBUTIONS}

Conception and design of the experiments: YY. Acquisition of the data: MS, YY. Analysis of the data: MS, YY, KN, YH. Interpretation of data: MS, YY, JT, FY.

\section{FUNDING}

This study was supported in part by JSPS KAKENHI Grant Number 26462804 (YY) from the Ministry of Education, Culture, Sports, Science and Technology of Japan.

\section{ACKNOWLEDGMENT}

We thank Dr. M. Naito of Nagasaki University (Nagasaki, Japan) for providing $\mathrm{pCEPA}$.

\section{SUPPLEMENTARY MATERIAL}

The Supplementary Material for this article can be found online at: http://journal.frontiersin.org/article/10.3389/fmicb.2016. 01146 


\section{REFERENCES}

Chang, M. C., Tsai, Y. L., Chen, Y. W., Chan, C. P., Huang, C. F., Lan, W. C., et al. (2013). Butyrate induces reactive oxygen species production and affects cell cycle progression in human gingival fibroblasts. J. Periodontal Res. 48, 66-73. doi: 10.1111/j.1600-0765.2012.01504.x

Charrier, Ć., Duncan, G. J., Reid, M. D., Rucklidge, G. J., Henderson, D., Young, P., et al. (2006). A novel class of CoA-transferase involved in short-chain fatty acid metabolism in butyrate-producing human colonic bacteria. Microbiology 152, 179-185. doi: 10.1099/mic.0.28412-28410

Duncan, S. H., Barcenilla, A., Stewart, C. S., Pryde, S. E., and Flint, H. J. (2002). Acetate utilization and butyryl coenzyme a $(\mathrm{CoA})$ :acetate-CoA transferase in butyrate-producing bacteria from the human large intestine. Appl. Environ. Microbiol. 68, 5186-5190. doi: 10.1128/AEM.68.10.5186-5190.2002

Eftimiadi, C., Tonetti, M., Cavallero, A., Sacco, O., and Rossi, G. A. (1990). Short-chain fatty acids produced by anaerobic bacteria inhibit phagocytosis by human lung phagocytes. J. Infect. Dis. 161, 138-142. doi: 10.1093/infdis/ 161.1.138

Fletcher, H. M., Morgan, R. M., and Macrina, F. L. (1997). Nucleotide sequence of the porphyromonas gingivalis W83 recA homolog and construction of a recA-deficient mutant. Infect. Immun. 65, 4592-4597.

Gardner, R. G., Russell, J. B., Wilson, D. B., Wang, G. R., and Shoemaker, N. B. (1996). Use of a modified Bacteroides-Prevotella shuttle vector to transfer a reconstructed beta-1,4-D-endoglucanase gene into Bacteroides uniformis and Prevotella ruminicola B14. Appl. Environ. Microbiol. 62, 196-202.

Gerhardt, A., Cinkaya, I., Linder, D., Huisman, G., and Buckel, W. (2000). Fermentation of 4-aminobutyrate by Clostridium aminobutyricum: cloning of two genes involved in the formation and dehydration of 4-hydroxybutyrylCoA. Arch. Microbiol. 174, 189-199. doi: 10.1007/s002030000195

Hendrickson, E. L., Xia, Q., Wang, T., Lamont, R. J., and Hackett, M. (2009). Pathway analysis for intracellular Porphyromonas gingivalis using a strain ATCC 33277 specific database. BMC Microbiol. 9:185. doi: 10.1186/1471-21809-185

Holt, S. C., Kesavalu, L., Walker, S., and Genco, C. A. (1999). Virulence factors of Porphyromonas gingivalis. Periodontol. 2000 20, 168-238. doi: 10.1111/j.16000757.1999.tb00162.x

Horton, R. M., Hunt, H. D., Ho, S. N., Pullen, J. K., and Pease, L. R. (1989). Engineering hybrid genes without the use of restriction enzymes: gene splicing by overlap extension. Gene 77, 61-68. doi: 10.1016/0378-1119(89)90359-4

How, K. Y., Song, K. P., and Chan, K. G. (2016). Porphyromonas gingivalis: an overview of periodontopathic pathogen below the gum line. Front Microbiol. 7:53. doi: $10.3389 /$ fmicb. 2016.00053

Imai, K., Yamada, K., Tamura, M., Ochiai, K., and Okamoto, T. (2012). Reactivation of latent HIV-1 by a wide variety of butyric acid-producing bacteria. Cell. Mol. Life Sci. 69, 2583-2592. doi: 10.1007/s00018-012-0936-932

Kumar, P. S. (2013). Oral microbiota and systemic disease. Anaerobe 24, 90-93. doi: 10.1016/j.anaerobe.2013.09.010

Kurita-Ochiai, T., Fukushima, K., and Ochiai, K. (1995). Volatile fatty acids, metabolic by-products of periodontopathic bacteria, inhibit lymphocyte proliferation and cytokine production. J. Dent. Res. 74, 1367-1373. doi: $10.1177 / 00220345950740070801$

Kurita-Ochiai, T., Ochiai, K., and Fukushima, K. (2000). Butyric-acid-induced apoptosis in murine thymocytes and splenic T- and B-cells occurs in the absence of p53. J. Dent. Res. 79, 1948-1954. doi: 10.1177/00220345000790 120501

Kurita-Ochiai, T., Seto, S., Suzuki, N., Yamamoto, M., Otsuka, K., Abe, K., et al. (2008). Butyric acid induces apoptosis in inflamed fibroblasts. J. Dent. Res. 87, 51-55. doi: 10.1177/154405910808700108

Lamont, R. J., and Jenkinson, H. F. (1998). Life below the gum line: pathogenic mechanisms of Porphyromonas gingivalis. Microbiol. Mol. Biol. Rev. 62, 12441263.

Lamont, R. J., and Jenkinson, H. F. (2000). Subgingival colonization by Porphyromonas gingivalis. Oral Microbiol. Immunol. 15, 341-349. doi: 10.1034/j.1399-302x.2000.150601.x

Le Chatelier, E., Nielsen, T., Qin, J., Prifti, E., Hildebrand, F., Falony, G., et al. (2013). Richness of human gut microbiome correlates with metabolic markers. Nature 500, 541-546. doi: 10.1038/nature12506
Louis, P., Duncan, S. H., McCrae, S. I., Millar, J., Jackson, M. S., and Flint, H. J. (2004). Restricted distribution of the butyrate kinase pathway among butyrateproducing bacteria from the human colon. J. Bacteriol. 186, 2099-2106. doi: 10.1128/JB.186.7.2099-2106.2004

MacLean, A. M., MacPherson, G., Aneja, P., and Finan, T. M. (2006), Characterization of the beta-ketoadipate pathway in Sinorhizobium meliloti. Appl. Environ. Microbiol. 72, 5403-5413. doi: 10.1128/AEM. 00580-586

Mathewson, N. D., Jenq, R., Mathew, A. V., Koenigsknecht, M., Hanash, A., Toubai, T., et al. (2016). Gut microbiome-derived metabolites modulate intestinal epithelial cell damage and mitigate graft-versus-host disease. Nat. Immunol. 17, 505-513. doi: 10.1038/ni.3400

Naito, M., Hirakawa, H., Yamashita, A., Ohara, N., Shoji, M., Yukitake, H., et al. (2008). Determination of the genome sequence of Porphyromonas gingivalis strain ATCC 33277 and genomic comparison with strain W83 revealed extensive genome rearrangements in P. gingivalis. DNA Res. 15, 215-225. doi: dsn013 [pii] 10.1093/dnares/dsn013

Nelson, K. E., Fleischmann, R. D., DeBoy, R. T., Paulsen, I. T., Fouts, D. E., Eisen, J. A., et al. (2003). Complete genome sequence of the oral pathogenic Bacterium Porphyromonas gingivalis strain W83. J. Bacteriol. 185, 5591-5601. doi: 10.1128/JB.185.18.5591-5601.2003

Niederman, R., Buyle-Bodin, Y., Lu, B. Y., Naleway, C., Robinson, P., and Kent, R. (1996). The relationship of gingival crevicular fluid short chain carboxylic acid concentration to gingival inflammation. J. Clin. Periodontol. 23, 743-749. doi: 10.1111/j.1600-051X.1996.tb00604.x

Niederman, R., Buyle-Bodin, Y., Lu, B. Y., Robinson, P., and Naleway, C. (1997). Short-chain carboxylic acid concentration in human gingival crevicular fluid. J. Dent. Res. 76, 575-579. doi: 10.1177/00220345970760010801

Pace, C. N., Vajdos, F., Fee, L., Grimsley, G., and Gray, T. (1995). How to measure and predict the molar absorption coefficient of a protein. Protein Sci. 4, 2411-2423. doi: 10.1002/pro.5560041120

Parales, R. E., and Harwood, C. S. (1993). Regulation of the pcaIJ genes for aromatic acid degradation in Pseudomonas putida. J. Bacteriol. 175, 5829-5838.

Peng, L., Li, Z. R., Green, R. S., Holzman, I. R., and Lin, J. (2009). Butyrate enhances the intestinal barrier by facilitating tight junction assembly via activation of AMP-activated protein kinase in Caco-2 cell monolayers. J. Nutr. 139, 16191625. doi: $10.3945 /$ jn. 109.104638

Plöger, S., Stumpff, F., Penner, G. B., Schulzke, J. D., Gäbel, G., Martens, H., et al. (2012). Microbial butyrate and its role for barrier function in the gastrointestinal tract. Ann. N. Y. Acad. Sci. 1258, 52-59. doi: 10.1111/j.17496632.2012.06553.x

Qin, J., Li, Y., Cai, Z., Li, S., Zhu, J., Zhang, F., et al. (2012). A metagenome-wide association study of gut microbiota in type 2 diabetes. Nature 490, 55-60. doi: 10.1038 /nature11450

Qiqiang, L., Huanxin, M., and Xuejun, G. (2012). Longitudinal study of volatile fatty acids in the gingival crevicular fluid of patients with periodontitis before and after nonsurgical therapy. J. Periodontal Res. 47, 740-749. doi: 10.1111/j.1600-0765.2012.01489.x

Scherf, U., and Buckel, W. (1991). Purification and properties of 4-hydroxybutyrate coenzyme a transferase from Clostridium aminobutyricum. Appl. Environ. Microbiol. 57, 2699-2702.

Siavoshian, S., Segain, J. P., Kornprobst, M., Bonnet, C., Cherbut, C., Galmiche, J. P., et al. (2000). Butyrate and trichostatin a effects on the proliferation/differentiation of human intestinal epithelial cells: induction of cyclin D3 and p21 expression. Gut 46, 507-514. doi: 10.1136/gut. 46.4.507

Singer, R. E., and Buckner, B. A. (1981). Butyrate and propionate: important components of toxic dental plaque extracts. Infect. Immun. 32, 458-463.

Socransky, S. S., and Haffajee, A. D. (2002). Dental biofilms: difficult therapeutic targets. Periodontol 2000 28, 12-55. doi: 10.1034/j.1600-0757.2002. 280102.x

Takahashi, N., Sato, T., and Yamada, T. (2000). Metabolic pathways for cytotoxic end product formation from glutamate- and aspartate-containing peptides by Porphyromonas gingivalis. J. Bacteriol. 182, 4704-4710. doi: 10.1128/JB.182.17.4704-4710.2000

Tonetti, M., Eftimiadi, C., Damiani, G., Buffa, P., Buffa, D., and Botta, G. A. (1987). Short chain fatty acids present in periodontal pockets may play a 
role in human periodontal diseases. J. Periodontal Res. 22, 190-191. doi: 10.1111/j.1600-0765.1987.tb01565.x

Travis, A. J., Kelly, D., Flint, H. J., and Aminov, R. I. (2015). Complete genome sequence of the human gut symbiont Roseburia hominis. Genome Announc. 3:e01286-15. doi: 10.1128/genomeA.01286-15

Walter, K. A., Nair, R. V., Cary, J. W., Bennett, G. N., and Papoutsakis, E. T. (1993). Sequence and arrangement of two genes of the butyrate-synthesis pathway of Clostridium acetobutylicum ATCC 824. Gene 134, 107-111. doi: 10.1016/0378-1119(93)90182-3

Yoshida, Y., Sato, M., Kezuka, Y., Hasegawa, Y., Nagano, K., Takebe, J., et al. (2016). Acyl-CoA reductase PGN_0723 utilizes succinyl-CoA to generate succinate semialdehyde in a butyrate-producing pathway of Porphyromonas gingivalis. Arch. Biochem. Biophys. 596, 138-148. doi: 10.1016/j.abb.2016.03.014

Yoshida, Y., Sato, M., Nagano, K., Hasegawa, Y., Okamoto, T., and Yoshimura, F. (2015). Production of 4-hydroxybutyrate from succinate semialdehyde in butyrate biosynthesis in Porphyromonas gingivalis. Biochim. Biophys. Acta 1850, 2582-2591. doi: 10.1016/j.bbagen.2015.09.019
Yoshida, Y., Suzuki, N., Nakano, Y., Shibuya, K., Ogawa, Y., and Koga, T. (2003). Distribution of Actinobacillus actinomycetemcomitans serotypes and Porphyromonas gingivalis in Japanese adults. Oral Microbiol. Immunol. 18, 135-139. doi: 10.1034/j.1399-302X.2003. 00034.x

Conflict of Interest Statement: The authors declare that the research was conducted in the absence of any commercial or financial relationships that could be construed as a potential conflict of interest.

Copyright (c) 2016 Sato, Yoshida, Nagano, Hasegawa, Takebe and Yoshimura. This is an open-access article distributed under the terms of the Creative Commons Attribution License (CC BY). The use, distribution or reproduction in other forums is permitted, provided the original author(s) or licensor are credited and that the original publication in this journal is cited, in accordance with accepted academic practice. No use, distribution or reproduction is permitted which does not comply with these terms. 